\title{
Evidence that cortical granule formation is a periovulatory event in marsupials
}

\author{
K. E. Mate ${ }^{1}$, I. Giles $^{1}$ and J. C. Rodger ${ }^{1,2}$ \\ ${ }^{* 1}$ Department of Biological Sciences, University of Newcastle, NSW, Australia, 2308; and \\ ${ }^{2}$ Department of Genetics, Southwest Foundation for Biomedical Research, PO Box 28147 ,
} San Antonio, TX 78228-0147, USA

\begin{abstract}
Summary. Formation of cortical granules was examined in superovulated oocytes from three marsupial species, brushtail possums (Trichosurus vulpecula) tammar wallabies (Macropus eugeniii) and grey short-tailed opossums (Monodelphis domestica) and in oocytes obtained during natural cycles in Macropus eugenii. Superovulation was induced by pregnant mares' serum gonadotrophin/gonadotrophin-releasing hormone (PMSG/GnRH) protocols and natural ovulation by removal of pouch young. Oocytes were collected after ovariectomy or by laparoscopically guided follicle aspiration into Hanks balanced salt solution (HBSS) supplemented with either $2.5 \%$ fetal calf serum (FCS) or $2.5 \%$ bovine serum albumin (BSA). Ovulated oocytes were collected by removing and flushing the oviducts with HBSS and fixed immediately for electron microscopy. There were no differences in the morphology or timing of formation of cortical granules between superovulated and naturally cycling animals. Cortical granules were absent from germinal vesicle (GV) stage follicular oocytes before the luteinizing hormone ( $\mathrm{LH})$ surge in all species. Dark cortical granules, similar in appearance to those seen in the oocytes of eutherian mammals, were found just beneath the plasma membrane ( 9 per $100 \mu \mathrm{m}$ of plasma membrane) of preovulatory oocytes at germinal vesicle, metaphase 1 or anaphase 1 stages. In addition, they contained a number of less electron-dense cortical granules ( 12 per $100 \mu \mathrm{m}$ plasma membrane). The cortical cytoplasm of preovulatory oocytes was rich in Golgi complexes actively involved in vesicle formation. Large numbers of dark cortical granules ( 90 per $100 \mu \mathrm{m}$ plasma membrane) were found only in ovulated oocytes. A small number of cortical granules of lighter electron density were also present in ovulated oocytes. This suggests that the marsupial oocyte is following a very different timetable for cortical granule formation and accumulation from eutherian mammals and that oocytes of marsupials may not achieve cytoplasmic maturity until after ovulation. The significance of these events for fertilization and development remains to be established.
\end{abstract}

Keywords: cortical granule; oocyte; marsupial; possum; wallaby; opossum

\section{Introduction}

The unfertilized oocytes of most vertebrates and invertebrates contain small, spherical, membranebound granules just beneath the plasma membrane. At fertilization these cortical granules fuse with the oolemma and release their contents into the perivitelline space. Release of cortical granules alters the functional properties of the zona pellucida so that supernumerary spermatozoa are

\footnotetext{
*Address for reprints and correspondence.
} 
prevented from penetrating (reviewed by Schuel, 1978, 1985; Gulyas, 1980; Wolf, 1981; Guraya, 1982; Schmell et al., 1983; Jaffe \& Gould, 1985; Cran, 1989).

Cortical granules appear early in oocyte development. In many mammals they are first seen in small multilaminar follicles (Szollosi, 1967; Zamboni, 1974), whereas in rodents they are found in unilaminar follicles (Szollosi, 1967; Odor \& Blandau, 1969). Their formation is associated with many active Golgi complexes in the peripheral cytoplasm of the growing oocyte. It has been suggested that multivesicular bodies (Adams \& Hertig, 1964; Szollosi, 1967), granular endoplasmic reticulum (Gulyas, 1980) and smooth endoplasmic reticulum (Cran, 1985; Hyttel et al., 1986) may also contribute to formation of cortical granules. The first evidence of formation of cortical granules is the presence of small Golgi vesicles and tubules filled with electron-dense material. These small bodies coalesce to form larger vacuole-like immature cortical granules. Condensation and further accumulation of the luminal contents of the fusing vesicles results in formation of the mature dense granules (Szollosi, 1967; Zamboni, 1972; Cran \& Moor, 1990). The population of cortical granules can be classified into dark or light forms (Cran \& Cheng, 1985; Ducibella et al., 1988b). It is not clear whether light and dark cortical granules represent separate, functionally distinct populations or different maturational stages of their development.

Just before ovulation in many species, cortical granules migrate and most come to lie very close to the cell membrane (Kruip et al., 1983; Cran \& Cheng, 1985; Hyttel et al., 1986; Cran \& Moor, 1990). Formation of cortical granules is completed by ovulation in most species although formation of cortical granules after ovulation has been reported in rabbits (Longo, 1974; Gulyas, 1980) and mouse oocytes (Zamboni, 1970). Quantitative studies of distribution of cortical granules in mice indicate that tubal oocytes do not continue to accumulate cortical granules (Nicosia et al., 1977) and that healthy oviductal oocytes at metaphase II have fewer cortical granules than germinal vesicle (GV) stage oocytes (Ducibella et al., 1988a, 1990a, 1990b). This results from formation of the cortical granule free domain above the meiotic spindle and prefertilization release of some cortical granules (Ducibella et al., 1988a, 1990b).

Cortical granules have been observed in secondary preovulatory oocytes from Didelphis virginiana (Rodger \& Bedford, 1982) and Sminthopsis crassicaudata (Breed \& Leigh, 1990). Release of cortical granules was shown to accompany fertilization in Didelphis but it is uncertain whether a strong block to polyspermy is established at the zona as a result of this (Rodger \& Bedford, 1982; Baggott et al., 1987). This study was initiated when we found that preovulatory oocytes from brushtail possums and tammar wallabies obtained for use in in vitro fertilization studies possessed few or no cortical granules and could not bind spermatozoa (Rodger, 1991). It was first assumed that collection and handling of the oocytes had led to premature release of cortical granules, but evidence is presented of very late formation of cortical granules in three marsupials: Trichosurus vulpecula, Macropus eugenii and Monodelphis domestica.

\section{Materials and Methods}

\section{Animals}

The source and housing of the brushtail possums (Trichosurus vulpecula) and tammar wallabies (Macropus eugenii) were as described previously (Rodger \& Mate, 1988; Mate \& Rodger, 1991). Grey short-tailed opossums (Monodelphis domestica) were colony bred and housed at the Southwest Foundation for Biomedical Research, San Antonio, Texas (Fadem et al., 1982; Cothran et al., 1985).

\section{Follicle stimulation}

Development of multiple follicles was stimulated with pregnant mares' serum gonadotrophin (PMSG) (Folligon: Intervet, Oss, The Netherlands) administered subcutaneously (possum: $10 \mathrm{iu}$; wallaby: $20 \mathrm{iu}$; opossum: $1 \mathrm{iu}$ ). Oocyte maturation and ovulation in the possum were induced by three intramuscular injections of $50 \mu \mathrm{g}$ synthetic gonadotrophin-releasing hormone (GnRH) (Fertagyl: Intervet, Oss, The Netherlands) three days after PMSG (Rodger \& Mate, 1988). Luteinizing-hormone-releasing hormone (LHRH) (Sigma, St Louis, MO, USA) was used to induce ovulation in the wallaby and opossum three days after PMSG (wallaby: $3 \times 30 \mu \mathrm{g}$ LHRH in oil, $3 \mathrm{~h}$ apart; 
opossum: $1 \times 20 \mu \mathrm{g}$ LHRH). Ovulation occurred $24 \mathrm{~h}$ after the first GnRH injection in PMSG-treated possums (Hayman \& Rodger, 1990) and 3 days after LHRH in opossums (J. C. Rodger, E. Robinson \& J. VandeBerg, unpublished). The interval from LHRH to ovulation in PMSG-primed wallabies has not been determined but data from naturally cycling animals suggests that ovulation occurs between 24 and $40 \mathrm{~h}$ after the $\mathrm{LH}$ peak (Sutherland $e t$ al., 1980; Tyndale-Biscoe \& Rodger, 1978).

Possum oocytes were examined at three stages of development:

(i) PMSG only-oocytes were collected 3 days after PMSG at the time when GnRH would normally be given;

(ii) preovulatory - oocytes were collected $18-24 \mathrm{~h}$ after first $\mathrm{GnRH}$ injection;

(iii) ovulated-- oocytes were flushed from the oviduct at either $6 \mathrm{~h}$ or $24 \mathrm{~h}$ after the estimated time of ovulation.

Wallaby and opossum oocytes from PMSG/LHRH-primed animals were examined at the preovulatory stage only. Preovulatory oocytes were collected from wallaby ovaries 24 or $48 \mathrm{~h}$ after first LHRH injection and from opossum ovaries 3 days after LHRH.

\section{Natural cycles}

Oocyte development was examined in two wallabies during cycles induced by removal of pouch young and intramuscular injection of $25 \mathrm{mg}$ bromocriptine (Sandoz, North Ryde, Australia) as described by Tyndale-Biscoe \& Hinds (1984). One preovulatory oocyte was obtained from a 4.9-mm follicle $1 \cdot 5$ days after detection of a new pouch young. Oocytes contained in follicles greater than $1-2 \mathrm{~mm}$ without any evidence of atresia at time of ovariectomy were classified as immature.

\section{Oocyte collection}

Anaesthesia was induced by $0.2 \mathrm{ml} \mathrm{kg}{ }^{-1}$ intramuscular injection of Zoletil 100 (tiletamine chlorhydrate $50 \mathrm{mg} \mathrm{ml}^{-1}$, zolazepam chlorhydrate $50 \mathrm{mg} \mathrm{ml}^{-1}$; Virbac, Australia) and maintained during surgery with $2 \cdot 5 \%$ Halothane (May $\&$ Bayer, Australia) in oxygen (CIG, Australia) delivered at 1 litre $\mathrm{min}^{-1}$. Laparoscopic examinations of ovaries were performed to confirm adequate follicle stimulation or ovulation. Follicular oocytes were collected by laparoscopically guided follicle aspiration or following ovariectomy into Hanks balanced salt solution (HBSS) supplemented with either $2 \cdot 5 \%$ fetal calf serum (FCS) or $2.5 \%$ bovine serum albumin (BSA). After ovariectomy, follicles were punctured with a 30 -gauge needle and flushed with HBSS until the oocyte was recovered. Heparin $\left(12.5 \mathrm{iu} \mathrm{ml}^{-1}\right)$ was included in the flushing medium as an anticoagulant.

Animals were killed by an intravenous overdose of sodium pentobarbitone (Euthatal $350,1 \mathrm{ml} \mathrm{per} 2.5 \mathrm{~kg}, \mathrm{May} \&$ Baker, West Footscray, Australia). The oviduct was removed and either fixed intact for electron microscopy or flushed via its uterine end using a needle and syringe containing HBSS and heparin to recover the oocyte(s).

\section{Electron microscopy}

Oocytes were fixed immediately for electron microscopy in $2 / 3$ Superfix at pH 7.6 (final concentrations: $0 \cdot 15$ mol sodium cacodylate $l^{-1} ; 1.8 \%$ paraformaldehyde; $0.01 \%$ picric acid; $3.2 \%$ glutaraldehyde; $1.7 \mathrm{mmol}^{\mathrm{Ca}} \mathrm{a}^{2+} 1^{-1}$ ) for $1 \mathrm{~h}$ at 4 C. Superfix has been used previously for fixation of mammalian embryos and ejaculated spermatozoa (Zamboni \& DeMartino, 1967) and provided superior primary fixation of marsupial oocytes compared with $3 \%$ glutaraldehyde in cacodylate, collidine or phosphate buffer. Calcium was included in the fixative to reduce loss of lipids and improve the preservation of mitochondria (Glauert, 1975). On some occasions, the entire ovary was fixed intact in $2 / 3$ Superfix overnight at $4 \mathrm{C}$ before dissection of the oocyte and its attached area of follicle wall. Post-fixation was in $1 \%$ OsO in $0.1 \mathrm{~mol}$ cacodylate buffer $1^{-1}$ for $1 \mathrm{~h}$ at $4^{\circ} \mathrm{C}$. This was followed by washing in distilled water and block staining with $0.5 \%$ uranyl acetate, dehydration and embedding in Spurr's resin. Ultrathin sections were placed on copper grids, stained with uranyl acetate and lead citrate and examined on Joel CX-100 electron microscope. Thick sections ( $1 \mu \mathrm{m})$ stained with $1 \%$ Toluidine blue in $1.0 \%$ sodium borate were used to assess the nuclear maturation of oocytes.

\section{Quantification of cortical granules}

An estimate of number of cortical granules was obtained by counting cortical granules per $100 \mu \mathrm{m}$ of plasma membrane. At least two different planes of section from a total of five preovulatory and five ovulated oocytes were used to collect the data. This quantification was used for developmental comparison purposes only and is not considered an accurate indication of total numbers of cortical granules owing to possible variations in their distribution throughout the cortex of the oocyte.

\section{Results}

The surface of marsupial oocytes in antral follicles was covered by densely distributed $2-3 \mu \mathrm{m}$ long microvilli. Possum oocytes contained an area of dense cortical cytoplasm where most organelles 
were concentrated. The interior of the oocytes was a large vacuolar region that contained only a few scattered organelles (Fig. 1a). Wallaby and opossum oocytes were also highly vacuolar but did not show a conspicuous band of cytoplasm around the cortex (Fig. 1b). Mitochondria and Golgi bodies were both closely associated with smooth endoplasmic reticulum in possum and wallaby oocytes (Fig. 2a-c).
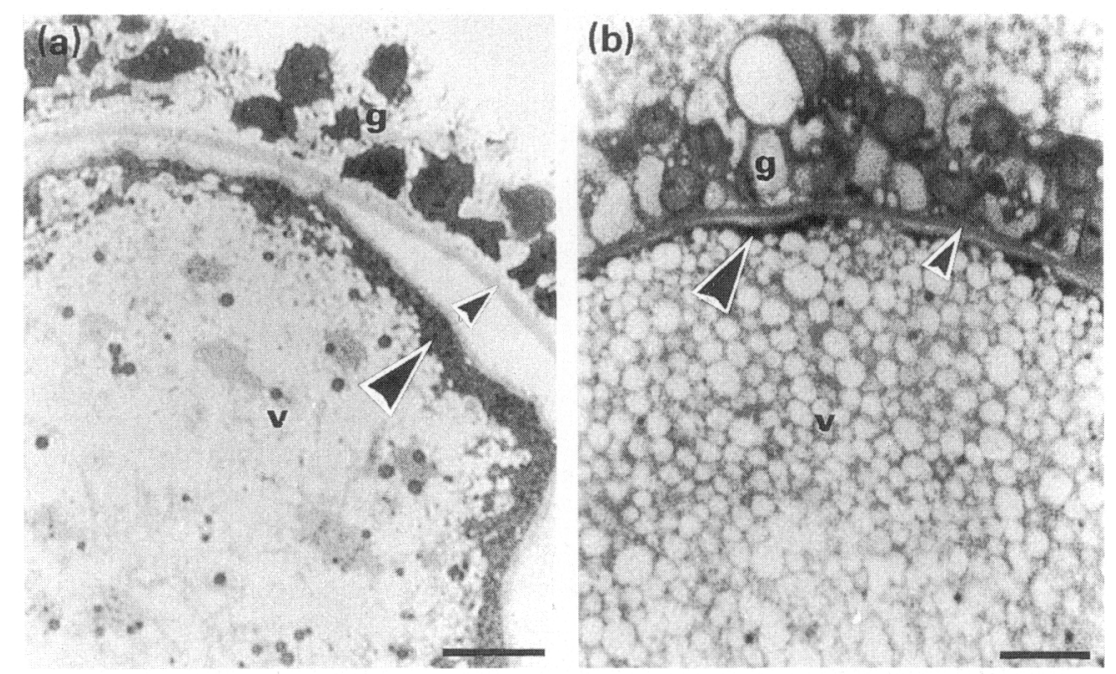

Fig. 1. Light micrographs of preovulatory oocytes surrounded by granulosa cells $(\mathrm{g})$ and zona pellucida (small arrowhead) from (a) the brushtail possum and (b) the short-tailed grey opossum. Most of the organelles in both species were contained within a band of cortical cytoplasm (large arrowheads); the remainder of the oocytes was occupied by large vacuolar areas (v). Bars $=20 \mu \mathrm{m}$.

\section{PMSG-only oocytes}

Immature possum oocytes (three animals: total nine oocytes) from PMSG-stimulated follicles (no GnRH) did not possess cortical granules (Fig. 2a). All nine oocytes contained a germinal vesicle. At this stage of development, oocytes contained many mitochondria with electron-diffuse matrix and highly secretory Golgi complexes (arrow Fig. 2a). The secretory vesicles associated with the Golgi complex ranged from $0 \cdot 1$ to $0 \cdot 2 \mu \mathrm{m}$ in diameter, contained lightly electron-dense material and were usually in close association with smooth endoplasmic reticulum.

\section{Preovulatory oocytes}

Just before the expected time of ovulation (18-24 h after first GnRH injection) possum follicular oocytes with a germinal vesicle ( $n=32$ oocytes) or with metaphase I or anaphase I chromosomes ( $n=8$ oocytes) possessed an average of nine dark cortical granules $(0 \cdot 2-0 \cdot 3 \mu \mathrm{m}$ diameter) per $100 \mu \mathrm{m}$ of plasma membrane. The dark cortical granules were unevenly distributed beneath the plasma membrane, generally in groups of 4-5 separated by $60-70 \mu \mathrm{m}$ lengths of plasma membrane free of cortical granules. Clusters of accumulating cortical granules or even individual cortical granules were not observed in the subcortical cytoplasm. At this stage, however, there were also less electron dense or light cortical granules $(0 \cdot 2-0 \cdot 3 \mu \mathrm{m}$ diameter) present just beneath the plasma membrane (arrowed Fig. 2b) at a density of 12 per $100 \mu \mathrm{m}$ plasma membrane. Mitochondria from preovulatory possum oocytes had concentrically arranged cristae and contained electron-dense material (Fig. 2b). Numbers of Golgi bodies remained high and they retained an active, secretory appearance in preovulatory oocytes (Fig. 2c). 

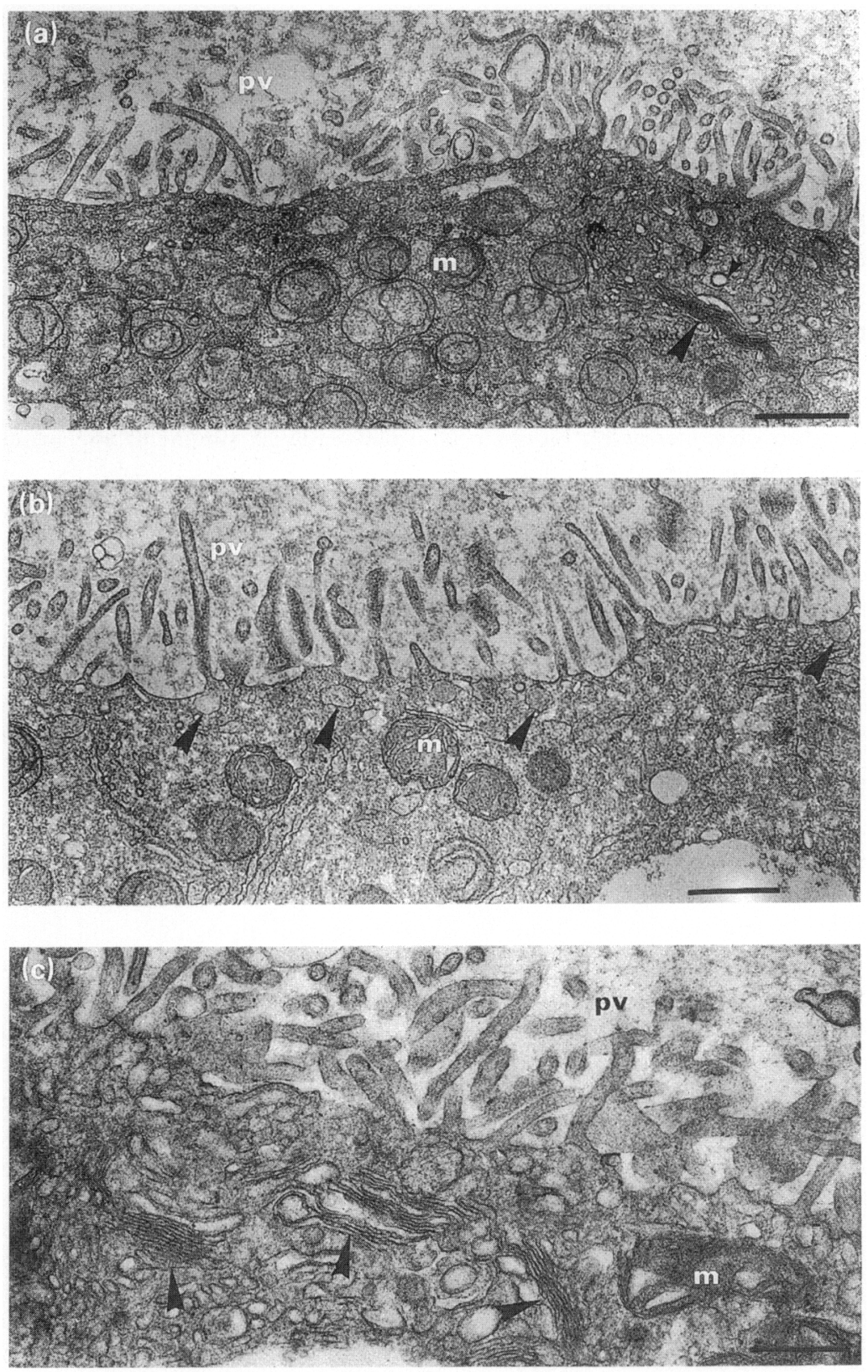

Fig. 2. The carly stages of cortical granule formation in oocytes from the brushtail possum. (a) Cortical cytoplasm and perivitelline space (pv) of an immature oocyte 3 days after pregnant mares` serum gonadotrophin (PMSG). The oocyte did not possess mature cortical granules beneath the plasma membrane but contained active Golgi complexes (large arrow) producing presumptive cortical granules (small arrowheads) and many mitochondria $(\mathrm{m})$. Bar $=1 \mu \mathrm{m}$. (b) Cortical cytoplasm and perivitelline space ( $\mathrm{pv}$ ) of a preovulatory oocyte $4 \mathrm{~h}$ before ovulation containing light cortical granules (arrowheads) just beneath the plasma membrane and mitochondria $(\mathrm{m})$. Bar $=1 \mu \mathrm{m}$. (c) An area of cortical cytoplasm adjacent to the perivitelline space $(p v)$ from a preovulatory oocyte as in (b) containing many active Golgi complexes (arrowheads) and associated vesicles. Bar $=0.5 \mu \mathrm{m}$. 
Preovulatory oocytes from PMSG/LHRH-primed wallabies (three animals: total five oocytes) were similar in appearance to preovulatory possum oocytes; they contained few mature cortical granules $(0 \cdot 2-0 \cdot 3 \mu \mathrm{m}$ diameter $)$ beneath the plasma membrane, although active Golgi complexes producing small precursors of cortical granules were prominent (Fig. 3a). Preovulatory oocytes from Monodelphis (Fig. 3c) possessed fewer cortical granules than possum oocytes at a similar stage but contained many Golgi and associated vesicular bodies (three animals: total six oocytes).

\section{Natural cycles}

Wallaby oocytes (two animals: total six oocytes) were from 1-2 mm follicles from ovaries induced to develop naturally by the removal of young from the pouch. However, these oocytes were almost identical in appearance to possum oocytes stimulated with PMSG alone; they did not possess cortical granules but contained a large number of Golgi and vesicular bodies (Fig. 3b). The mitochondria, however, contained a more electron dense matrix similar in appearance to that of preovulatory possum oocytes.

A preovulatory oocyte from a $4.9 \mathrm{~mm}$ naturally induced follicle in the wallaby could not be distinguished from PMSG/LHRH-induced preovulatory oocytes. The oocyte contained fewer mature cortical granules beneath the plasma membrane than observed in preovulatory possum oocytes. However, the cortical cytoplasm contained active Golgi and vesicular bodies.

\section{Ovulated oocytes}

The presence of cortical granules in ovulated oocytes was examined in the brushtail possum only. A total of nine oocytes from five animals were collected 6-12 h after ovulation: five with late prophase I or metaphase I chromosomes and four with a first polar body and thin covering of mucoid coat. All oocytes contained large numbers of electron-dense mature cortical granules $(0 \cdot 2-$ $0.3 \mu \mathrm{m}$ diameter) close to the plasma membrane (Fig. $3 \mathrm{~d}$ ). The mature ovulated oocytes contained approximately 90 cortical granules per $100 \mu \mathrm{m}$ of plasma membrane arranged in a single continuous layer beneath the plasma membrane. A further five oocytes with polar body and mucoid coat were recovered approximately $24 \mathrm{~h}$ after ovulation. Although these oocytes were beginning to show signs of degeneration, they retained similar numbers of cortical granules.

After ovulation, Golgi complexes, and to a lesser extent mitochondria, decreased in number in the cortical cytoplasm and the mitochondria became closely associated with and surrounded by microfilaments (Fig. 3d, e).

\section{Discussion}

Cortical granules of marsupials were found to be spherical, membrane-bound organelles with similar morphology to those of eutherians. The size of the cortical granules, $0 \cdot 2-0 \cdot 3 \mu \mathrm{m}$ diameter, was comparable to those of pigs (Cran \& Cheng, 1985) but slightly smaller than those of most eutherians, cortical granules of which generally range from 0.2 to $0.8 \mu \mathrm{m}$ diameter (Sathananthan \& Trounson, 1982; Cherr et al., 1988; Ducibella et al., 1988a, 1988b).

In the marsupials studied here, cortical granules were closely associated with Golgi complexes and smooth endoplasmic reticulum in a similar manner to that described in domestic species with long cycles such as cows and pigs (Cran \& Cheng, 1985; Hyttel et al., 1986). However, compared with eutherian mammals, formation of cortical granules did not begin until a much later stage of follicle development. Cortical granules were first detected in oocytes from the brushtail possum, tammar wallaby and opossum after the LH surge. Migration of cortical granules to their final position close to the plasma membrane appeared to occur immediately after their formation. The maximum number of mature peripherally positioned cortical granules was observed in ovulated oocytes that had undergone the first meiotic division. 

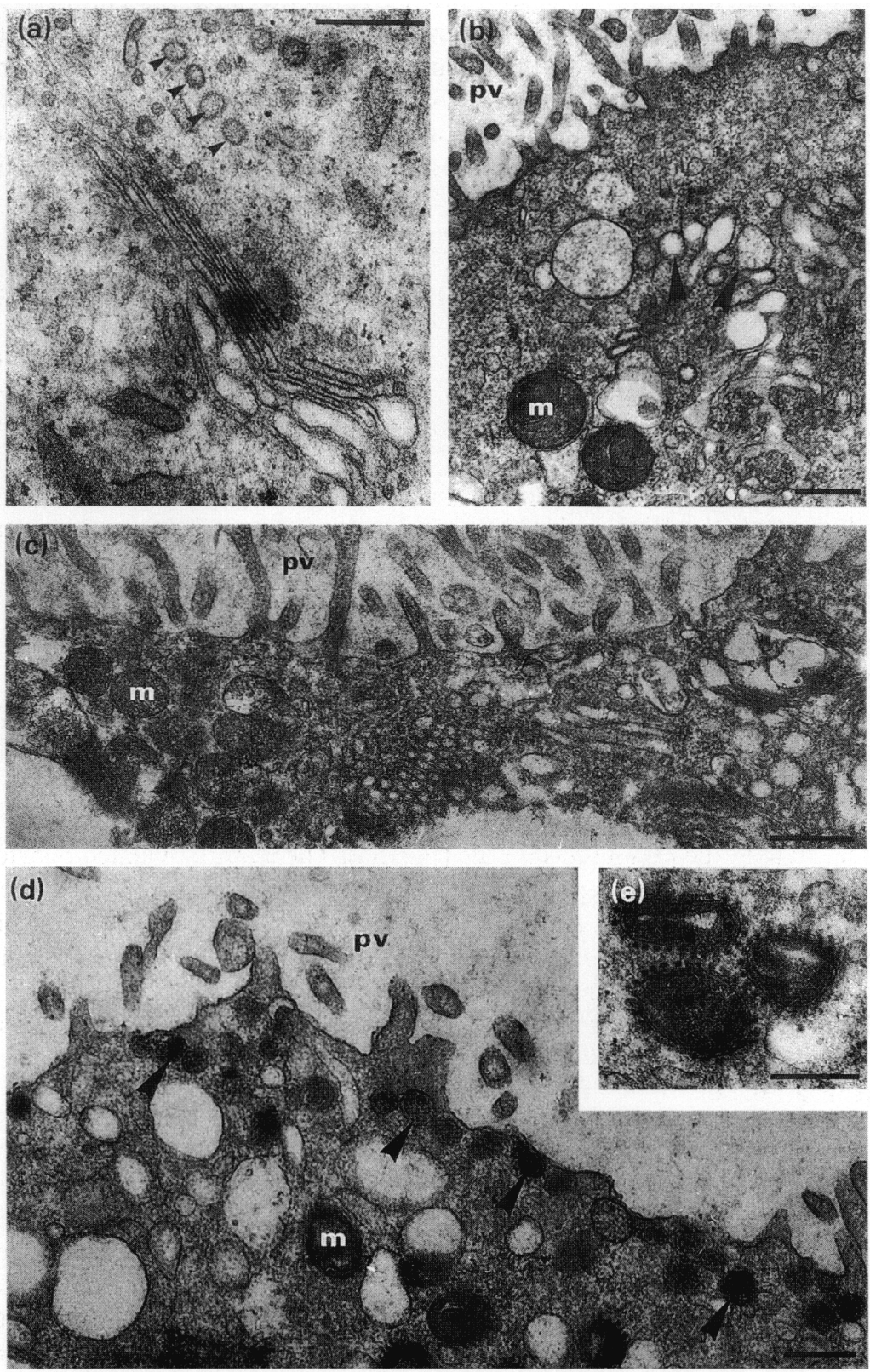

Fig. 3. (a) An active Golgi complex from a preovulatory pregnant mares' serum gonadotrophin/ gonadotrophin-releasing hormone (PMSG/LHRH)-primed tammar wallaby oocyte. The Golgi complex was producing small cortical granule precursors (arrowheads). (b) Cortical cytoplasm and perivitelline space ( $\mathrm{pv}$ ) from an immature wallaby oocyte from a natural cycle containing vesicular bodies (arrowheads) and mitochondria $(\mathrm{m})$. The oocyte did not contain cortical granules. (c) An area of cortical cytoplasm adjacent to the perivitelline space (pv) from a preovulatory opossum oocyte. Cortical granules were absent but there were many Golgi complexes, multivesicular bodies and mitochondria $(\mathrm{m})$. (d) A region of cortical cytoplasm from an ovulated possum oocyte with mature, dark cortical granules (arrowheads) beneath the plasma membrane. The oocyte also contained mitochondria (m) surrounded by microtubules. (e) Detail of mitochondria surrounded by microfilaments from the ovulated possum oocyte in (d). Bars $=0.5 \mu \mathrm{m}$. 
These findings represent a significant departure from the timing of formation of cortical granules in eutherian mammals. Although there is considerable variation between eutherian species, oocytes of preovulatory eutherians possess close to their final number of cortical granules and can be penetrated and fertilized (Moore \& Bedford, 1978; Berrios \& Bedford, 1979). Formation of cortical granules also appears to occur late in the dasyurid marsupial, Sminthopsis crassicaudata, but in this species it is before ovulation. In preovulatory follicles, cortical granules are conspicuous in secondary oocytes (first polar body stage) but appear to be absent from primary oocytes (germinal vesicle stage) (compare Figs 3 and 4 and Breed \& Leigh, 1990). A similar timing of formation of cortical granules probably also occurs in opossums. Preovulatory oocytes from Didelphis virginiana, collected as part of the study of Rodger \& Bedford (1982), contained a large number of cortical granules (Fig. 4, this study).

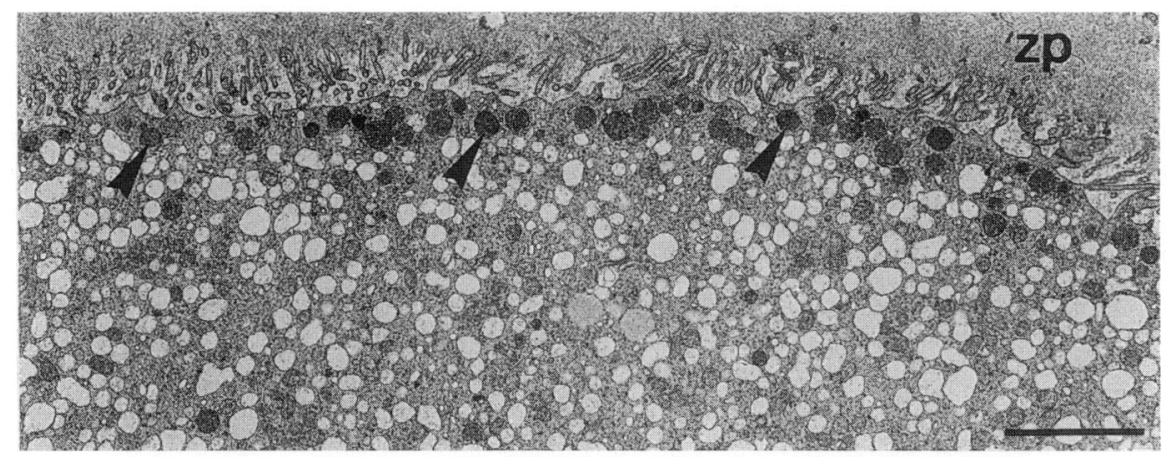

Fig. 4. An area of cortical cytoplasm of a preovulatory oocyte from Didelphis virginiana collected at a natural cycle. The oocyte was surrounded by a zona pellucida (zp) and contained large numbers of dark cortical granules (arrowheads) beneath the plasma membrane. Unpublished micrograph from the study of Rodger \& Bedford (1982). Bar $=1 \mu \mathrm{m}$.

Cortical granules of marsupials were of two types: light and dark. Early in the process of accumulation of cortical granules the light form predominated. As their formation and accumulation continued, the number of darker electron-dense cortical granules increased, so that after ovulation most cortical granules were of the dark form. However, a small number of cortical granules of various lighter densities persisted. It is suggested, therefore, that light cortical granules may represent an immature form, which are transformed during maturation to the dark form. Similar morphological variation has been reported for cortical granules of eutherians, but it is unclear whether this represents a functional or a maturational distinction. The presence of newly formed cortical granules of different diameters and electron density near Golgi complexes (Szollosi, 1967) and the marked increase in the dark:light ratio after ovulation in pigs (Cran \& Cheng, 1985) suggests the latter. However, mature mouse oocytes do not acquire an increased number of dark granules (Ducibella et al., 1988b) and the light cortical granules undergo preferential premature release (Ducibella et al., 1990b), suggesting a functional difference in this species.

Late development of cortical granules in marsupials is surprising as fertilization must take place in a narrow time band between ovulation and the deposition of the mucoid coat on the oocyte by cells of the oviduct (Rodger \& Bedford, 1982; Baggott $e$ t al., 1987). It would thus seem reasonable to expect that the oocyte released at ovulation would be fully capable of fertilization and of mounting a block to polyspermy. It has been suggested (Rodger \& Bedford, 1982; Selwood, 1982) that the corticalgranule-controlled zona block to polyspermy may not be strong in marsupials. The mucoid coat, a mucopolysaccharide secreted by the oviduct, may play an important secondary role in the block to polyspermy (Rodger \& Bedford, 1982; Selwood, 1982; Baggott et al., 1987; Breed \& Leigh, 1990) by trapping supernumerary spermatozoa in its initial layers. 
Although it is not discounted, it is unlikely that the timing of events of oocyte maturation described here were an artefact of the superovulation techniques used. Similar superovulation protocols are routinely used for the study of oocytes in eutherian species with little or no alteration to nuclear and cytoplasmic maturation (Hyttel et al., 1986). Examination of unstimulated ovaries from the tammar wallaby has confirmed the absence of cortical granules from all small and moderate sized antral follicles. Similarly, preovulatory oocytes from natural cycles conform to the same pattern of cortical granule formation, although the availability of this material is limited owing to the monovulatory nature of the Australian species.

The timing of formation of cortical granules may be an important indicator of significant maturational events occurring in late preovulatory and recently ovulated marsupial oocytes. We consider that the difficulties we have experienced achieving binding of spermatozoon and oocyte and in vitro fertilization with preovulatory marsupial oocytes may be due, at least in part, to immaturity of the oocytes.

This study was supported by grants to J. C. Rodger from the Australian Research Council and the Science and Technology Collaboration Programme of the Department of Industry, Technology and Commerce. K. E. Mate is the recipient of an Australian Postgraduate Research Award. The project had the approval of the University of Newcastle and Southwest Foundation for Biomedical Research Animal Care and Ethics Committees and the National Parks and Wildlife Service of NSW.

\section{References}

Adams, C.E. \& Hertig, A.T. (1964) Studies on guinea pig oocytes. 1. Electron microscopic observations on the development of cytoplasmic organelles in oocytes of primordial and primary follicles. Journal of Cell Biology 21, 397-427.

Baggott, L.M., Davis-Butler, S. \& Moore, H.D.M. (1987) Characterization of oestrus and timed collection of oocytes in grey short-tailed opossum, Monodelphis domestica. Journal of Reproduction and Fertility 79, $105-114$

Berrios, M. \& Bedford, J.M. (1979) Oocyte maturation: aberrant post-fusion responses of the rabbit primary oocyte to penetrating spermatozoa. Journal of Cell Science 39, 1-12.

Breed, W.G. \& Leigh, C.M. (1990) Morphological changes in the oocyte and its surrounding vestments during in vivo fertilization in the dasyurid marsupial Sminthopsis crassicaudata. Journal of Morphology 204, 177-196.

Cherr, G.N., Drobnis, E.Z. \& Katz, D.F. (1988) Localization of cortical granule constituents before and after exocytosis in the hamster egg. Journal of Experimental Zoology 246, 81-93.

Cothran, E.G., Aivaliotis, M.J. \& Vandeberg, J.L. (1985) The effects of diet on growth and reproduction in grey short-tailed opossums (Monodelphis domestica). Journal of Experimental Zoology 236, 103-114.

Cran, D.G. (1985) Qualitative and quantitative structural changes during pig oocyte maturation. Journal of Reproduction and Fertility 74, 237-245.

Cran, D.G. (1989) Cortical granules during oocyte maturation and fertilization. Journal of Reproduction and Fertility, Supplement 38, 49-62.

Cran, D.G. \& Cheng, W.T.K. (1985) Changes in cortical granules during porcine oocyte maturation. Gamete Research 11, 311-319.
Cran, D.G. \& Moor, R.M. (1990) Programming the oocyte for fertilization. In Fertilization in Mammals, pp. 35 - 47. Eds B. D. Bavister, J. Cummins \& E. R. S. Roldan. Serono Symposia USA, Massachusetts.

Ducibella, T., Anderson, E., Albertini, D.F., Alberg, J.A. \& Rangarajan, S. (1988a) Quantitative studies of changes in cortical granule number and distribution in the mouse oocyte during meiotic maturation. Developmental Biology 130, 184-197.

Ducibella, T., Rangarajan, S. \& Anderson, E. (1988b) The development of mouse oocyte cortical reaction competence is accompanied by major changes in cortical vesicles and not cortical granule depth. Developmental Biology 130, 789- 792.

Ducibella, T., Duffy, P., Reindollar, R. \& Su, B. (1990a) Changes in the distribution of mouse oocyte cortical granules and ability to undergo the cortical reaction during gonadotropin-stimulated meiotic maturation and aging in vivo. Biology of Reproduction 43, $870-876$.

Ducibella, T., Kurasawa, S., Rangarajan, S., Kopf, G.S. \& Schultz, R.M. (1990b) Precocious loss of cortical granules during mouse oocyte meiotic maturation and correlation with an egg-induced modification of the zona pellucida. Developmental Biology 137, $46-55$.

Fadem, B.H., Trupin, G.L., Meliniak, E., VandeBerg, J.L. \& Hayssen, V. (1982) Care and breeding of the grey, short-tailed opossum (Monodelphis domestica). Laboratory' Animal Science 32, 405-409.

Glauert, A.M. (1975) Fixation, Dehydration and Embedding of Biological Specimens. North-Holland, Amsterdam.

Gulyas, B.J. (1980) Cortical granules of mammalian eggs. International Review of Cytology 63, 357--392.

Guraya, S.S. (1982) Recent progress in structure, origin, composition and function of cortical granules in 
animal eggs. International Review of Cytology 78, 257360 .

Hayman, D.L. \& Rodger, J.C. (1990) Meiosis in male and female Trichosurus vulpecula (Marsupiala). Heredity 64, 251-254.

Hyttel, P., Callesen, H. \& Greve, T. (1986) Ultrastructural features of preovulatory oocyte maturation in superovulated cattle. Journal of Reproduction and Ferility 76, 645-656.

Jaffe, L.A. \& Gould, M. (1985) Polyspermy-preventing mechanisms. In Biology of Fertilization: the Fertilization Response of the Egg, Vol. 3, pp. 223-250. Eds C. B. Metz \& A. Monroy. Academic Press, New York.

Kruip, T.A.M., Cran, D.G., Van Beneden, T.H. \& Dieleman, S.J. (1983) Structural changes in bovine oocytes during final maturation in vivo. Gamete Research 8, 29-47.

Longo, F.J. (1974) Ultrastructural changes in rabbit eggs aged in vivo. Biology of Reproduction 11, 22-39.

Mate, K.E. \& Rodger, J.C. (1991) Stability of the acrosome of the brush-tailed possum (Trichosurus vulpecula) and tammar wallaby (Macropus eugenii) in vitro and after exposure to conditions and agents known to cause capacitation or acrosome reaction of eutherian spermatozoa. Journal of Reproduction and Fertility 91, 4148.

Moore, H.D.M. \& Bedford, J.M. (1978) Ultrastructure of the equatorial segment of hamster spermatozoa during penetration of oocytes. Journal of Ultrastructure Research 62, $110-117$.

Nicosia, S.V., Wolf, D.P. \& Inoue, M. (1977) Cortical granule distribution and cell surface characteristics in mouse eggs. Developmental Biology 57, 56-74.

Odor, D.L. \& Blandau, R.J. (1969) Ultrastructural studies on fetal and early post natal mouse ovaries. II. Cytodifferentiation. American Journal of Anatomy $125,177-216$.

Rodger, J.C. (1991) Fertilization of marsupials. In $A$ Comparative Overview of Mammalian Fertilization, pp. 117-135. Eds B. Dunbar \& M. O'Rand. Plenum Press, New York.

Rodger, J.C. \& Bedford, J.M. (1982) Separation of sperm pairs and sperm-egg interaction in opossum, Didelphis virginiana. Journal of Reproduction and Fertility 64, 171. 179.

Rodger, J.C. \& Mate, K.E. (1988) A PMSG/GnRH method for the superovulation of the monovulatory brush-tailed possum (Trichosurus vulpecula). Journal of Reproduction and Fertility $\mathbf{8 3}, 885-891$.

Sathananthan, A.H. \& Trounson, A.O. (1982) Ultrastructural observations on cortical granules in human follicular oocytes cultured in vitro. Gamete Research 5, 191-198.

Schmell, E.D., Gulyas, B.J. \& Hedrick, J.L. (1983) Egg surface changes during fertilization and the molecular mechanism of the block to polyspermy. In Mechanism and Control of Animal Fertilization, pp. 365-413. Ed. J. F. Hartmann. Academic Press, New York.

Schuel, H. (1978) Secretory functions of egg cortical granules in fertilization and development: a critical review. Gamete Research 1, 299-382.

Schuel, H. (1985) Function of egg cortical granules. In Biology of Fertilization: the Fertilization Response of the Egg, Vol. 3, pp. 1-43. Eds C. B. Metz \& A. Monroy. Academic Press, New York.

Selwood, L. (1982) A review of maturation and fertilization in marsupials with special reference to the dasyurid: Antechinus stuartii. In Carnivorous Marsupials, Vol. 1, pp. 65-76. Ed. M. Archer. Royal Zoological Society NSW, Sydney.

Sutherland, R.L., Evans, S.M. \& Tyndale-Biscoe, C.H. (1980) Macropodid marsupial luteinizing hormone: validation of assay procedures and changes in concentrations in plasma during the oestrous cycle in the female tammar wallaby (Macropus eugenii). Journal of Endocrinology 86, 112.

Szollosi, D. (1967) Development of cortical granule and the cortical reaction in rat and hamster eggs. Anatomical Record 159, 431-446.

Tyndale-Biscoe, C.H. \& Hinds, L.A. (1984) Seasonal patterns of circulating progesterone and prolactin and response to bromocriptine in the female tammar, Macropus eugenii. General and Comparative Endocrinology 53, 58-68.

Tyndale-Biscoe, C.H. \& Rodger, J.C. (1978) Differential transport of spermatozoa into the two sides of the genital tract of a monovular marsupial, the tammar wallaby (Macropus eugenii). Journal of Reproduction and Fertility 52, 3743.

Wolf, D.P. (1981) The mammalian egg's block to polyspermy. In Fertilization and Embryonic Development In Vitro, pp. 183-197. Eds L. Mastroianni \& J. D. Biggers. Plenum Press, New York.

Zamboni, L. (1970) Ultrastructure of mammalian oocytes and ova. Biology of Reproduction Supplement 2, 44-63.

Zamboni, L. (1972) Comparative studies on the ultrastructure of mammalian oocytes. In Oogenesis, pp. 5-45. Eds J. D. Biggers \& A. W. Schuetz. University Park Press, Baltimore.

Zamboni, L. (1974) Fine morphology of the follicle wall and follicle cell-oocyte association. Biology of Reproduction 10, 125-149.

Zamboni, L. \& De Martino, C. (1967) Buffered picric acid-formaldehyde: a new, rapid fixative for electron microscopy. Journal of Cell Biology 35, 148a.

Received 22 May 1991 